\title{
EVALUATION OF QUALITY MANAGEMENT IN THE FOOD INDUSTRY A COMBINATION OF AHP AND UTILITY ANALYSIS
}

\author{
Oliver Meixner*, Siegfried Pöchtrager and Rainer Haas \\ Institute of Marketing and Innovation \\ University of Natural Resources and Life Sciences \\ Vienna, Austria \\ E-mail: oliver.meixner@boku.ac.at
}

\begin{abstract}
The following study focuses on the evaluation of the elements of a comprehensive quality management model by use of two different evaluation methods. Quality management is an important task within a company. In this respect, the combination of methods delivered priorities for the quality management model with higher validity compared to approximations out of only one evaluation method. Keywords: Food industry, quality management, method combination
\end{abstract}

\section{Introduction}

A well working quality management $(\mathrm{QM})$ system is one of the most important tasks in the food industry and it is a pre-condition for safe and secure foods. The more positive signals are sent to consumers (key information in view of trustworthiness and given quality expectations of consumers), the less risks are assumed to be connected to this food products (Espejel et al., 2009). This is even more important if consumers are not able to assess quality aspects and internal corporate information related to the food product quality (Terlaak and King, 2006).

Total quality management (TQM) systems are the state of the art of quality management in the food industry. However, TQM is connected to several myths and misunderstandings (Addey, 2000). As Bayazit and Karpak (2007) point out, it is possible to achieve an additional corporate benefit through TQM in view of a long term competitive advantage. However, there are important critical success factors (Yusof and Aspinwall, 2000), such as the human factors "management" and "employees" (Wali et al., 2003; Wilcock et al., 2010), the customers/consumers and their wishes and demands (Brown and Dalluege, 2004), highly structured QM processes, also in connection with QM certification (Fotopoulos and Psomas, 2010; Albersmeier, 2010). Many authors investigated the critical success factors for QM, e.g. Wali et al. (2003). However, only few studies are available approximating the importance of these success factors in view of effectiveness and efficiency of a given QM system. One example is the study of Pöchtrager et al. (2004) evaluating the success factors (including approximating their importance) of the EFQM model, i.e. the model of the European Foundation for Quality Management.

The main aims of the study presented herein (Pöchtrager, 2011) were twofold: At first, a comprehensive model of influencing factors was developed summarizing the state of the art of QM publications of the last decades. Subsequently, the validity of this model and the importance of the integrated influencing factors were evaluated by in-depth qualitative interviews (incl. subjective evaluations) of experts aggregating expert knowledge of the dairy sector in Austria. This article focuses on the second aim, the evaluation findings.

\section{The quality management model}

The investigated TQM model was developed based on an in-depth literature analysis (amongst others: Pöchtrager et al., 2004; Bayazit and Karpak, 2007; Albersmeier et al., 2010; Jha and Kumar, 2010; Tähkäpää et al., 2009; Rampersad, 2008; Omachonu et al., 2004; Khadndke, 1998). It consists of the following influencing factors for corporate quality management systems, whereby EN stand for "endogenous factors", EX(corp) for "corporate environment", EX(sys) for "system framing institutions", and SYS for system immanent factors (the relevant study by Pöchtrager, 2011, was written in German; the interpretation of the English translation of the factors might slightly differ form the original Ger-

\footnotetext{
${ }^{*}$ Corresponding author
} 
man denomination). For the first time, factors influencing a corporate quality management system were summarized into 3 categories (endogenous, exogenous, and system immanent):

Table 1. Quality management model / influencing factors

\begin{tabular}{llc}
\hline endogenous & exogenous & system immanent \\
\hline EN1: Management & EX1(co): Consumer & SYS1: Processes / documen- \\
EN2: Employees & EX2(co): Food retailing & tation \\
EN3: QM-responsible & EX3(co): Suppliers, co-operations, and their & SYS2: Measurement, analy- \\
EN4: Financial resources / quality & market position & sis, and improvement \\
costs & EX4(co): Society & \\
EN5: Resources for the infrastruc- & EX5(co): Market position of the company & \\
ture and working environment & EX6(sys): Special interest group & \\
EN6: Product requirements & EX7(sys): Control agency & \\
EN7: Company size & EX8(sys): Accreditation body & \\
& EX9(sys): Legislative body / standard owner & \\
\hline
\end{tabular}

Source: Pöchtrager (2011)

Out of this classification, a comprehensive TQM model embodying all relevant influencing factors can be provided. Taken relevant publications, no weighting of the model factors are available. The main task of the study by Pöchtrager (2011) was therefore to approximate the influencing power of the model elements (in view of a corporate quality management system). It is clear that companies of different economic sectors might have different perspectives and opinions under varying conditions. In general, the validity of the approximations is limited to specific pre-conditions: (a) The evaluation should be done by a homogenous group of decision makers, (b) the economic market conditions of the included companies must be comparable, (c) the general conditions (society, culture, etc.) should be comparable. Only if these conditions are fulfilled a group evaluation can be aggregated to estimate the "true" priorities of the elements of the TQM model. Therefore, the empirical field of this study are Austrian dairies; all estimations are valid for this sector only. The evaluation was done by the responsible quality managers of the dairies; the approximations represent the point of view of the QM department of the companies, other departments might provide different approximations.

In total, 10 interviews were conducted; the 10 most important companies were included into the sample covering about $90 \%$ of the total Austrian milk market. As a result, the findings provide a valid picture for the Austrian milk market based on estimations of the responsible quality managers.

\section{Methodology}

The TQM model can be interpreted as a decision hierarchy (see fig. 1), where the overall goal is the approximation of the importance of the influencing factors. The categories "endogenous", "exogenous", and "system immanent" represent the $1^{\text {st }}$ hierarchy level. The "exogenous factors" are subdivided into the sub-group $\left(2^{\text {nd }}\right.$ hierarchy level $)$ "corporate environment" and "system framing institutions". The factors $\mathrm{EN}_{\mathrm{i}}, \mathrm{EX}_{\mathrm{i}}$, and $\mathrm{SYS}_{\mathrm{i}}$ form the $3^{\text {rd }}$ hierarchy level. The main focus of the study is the approximation of the priorities of $\mathrm{EN}_{\mathrm{i}}, \mathrm{EX}_{\mathrm{i}}$, and $\mathrm{SYS}_{\mathrm{i}}$. The assumption is that factors with higher preference have a higher influence on the success or failure of a quality management system compared to factors with significantly lower preference.

Obviously, the aim of this decision hierarchy is not to evaluate alternatives. The aim is to approximate the importance of the hierarchy elements. We can use a wide range of decision methods to estimate the priorities of the elements. For our purpose, a twofold evaluation process was carried out: First, the importance of the influencing factors $\mathrm{EN}_{\mathrm{i}} \cdot \mathrm{EX}_{\mathrm{i}}$ and $\mathrm{SYS}_{\mathrm{i}}$ ( $3^{\text {rd }}$ hierarchy level) was estimated by use of a very simple, crude evaluation technique, the multi attribute utility analysis (MAUA). After that, the Analytic Hierachy Process was used to re-evaluate the importance of all elements of the hierarchy using pairwise comparisons. The evaluators were then confronted with the outcomes of both analytical tools and could refine their judgments interactively. The whole evaluation process and data collection was carried out by use of a standard spreadsheet program.

The reason for this complex evaluation process is simple: As no quantitative data are available, the interviewed quality managers had to make subjective evaluations based on their own experience. 
Whenever we use intuition for our evaluations the latent risk of misinterpretations is evident. As the approximation should be valid for a whole food sector, it was mandatory to get approximations representing the "true" priorities as far as possible. The following empirical results show that this twofold evaluation process can reduce the risk of invalid and/or random estimations to a minimum. Some authors, too, stress the advantages of combining methods to increase validity (see e.g., Thurmond, 2001).

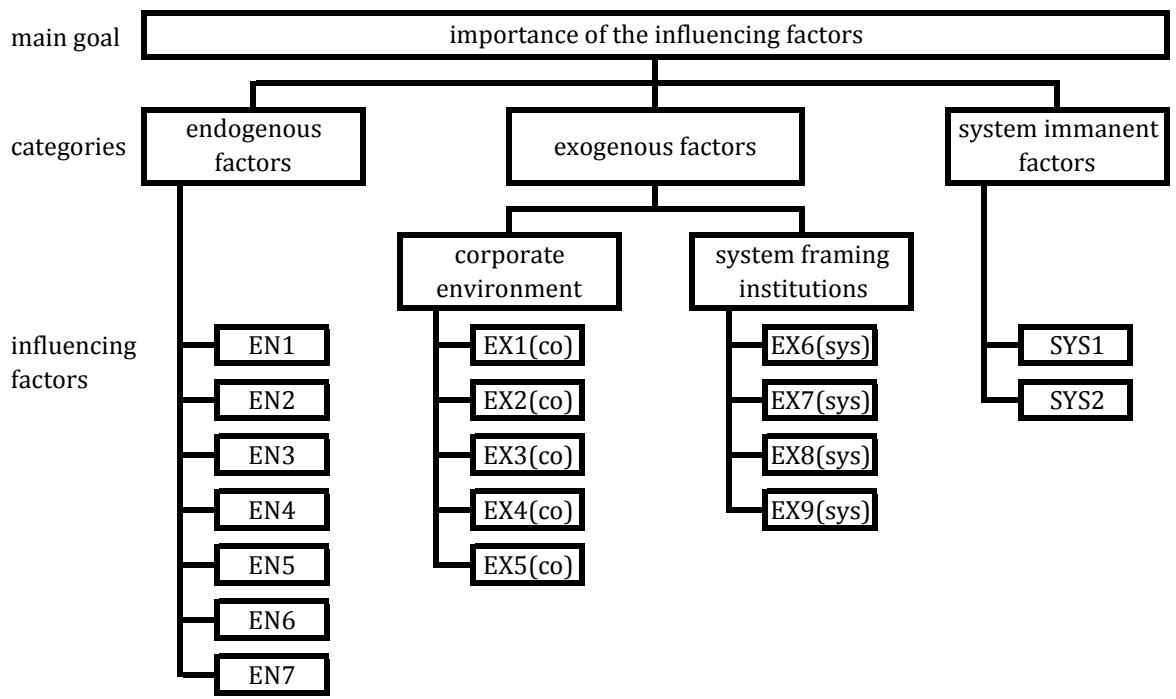

Fig. 1. Quality management model / decision hierarchy (Pöchtrager. 2011)

\section{Empirical findings}

Multi attribute utility analysis (MAUA): Usually, the MAUA is used to evaluate different alternatives in view of their ability to more or less fulfill a defined goal. For this purpose, the aggregated Utility $U_{i}$ of alternative $i$ is calculated for $k$ objectives and the weight of objective $h$ (denoted as $\phi_{h}$ ) by use of the following additive formula:

$$
\bigcup_{i}={ }_{h=1}{ }_{h} \times U_{i h}
$$

However, in our case the interesting variable is $\phi_{h}$. The approximation of $\phi_{h}$ was done by use of a simple interval scale $(0 \ldots 100)$, where 0 means no importance of an element (i.e. the influencing factor) and 100 is the highest importance ratio. $\phi_{h}$ was then estimated by dividing the single scale value by the total sum of all scale values with

$k$

$$
h=1
$$

In total, the 10 participating quality managers estimated ${ }_{h i}$ for all $h$ influencing factors. These priorities were then aggregated to ${ }_{h}^{-}$by use of the arithmetic mean:

$n$

$$
-_{h}=\frac{i_{i=1}^{h i}}{n}, i=1 \ldots 10
$$

Analytic hierarchy process (AHP): Confirming DYER und FORMAN (1991) „AHP allows decision makers to set priorities and make choices on the basis of their objectives and knowledge and experiences in a way that is consistent with their intuitive thought process“. And „It organizes the basic rationality by breaking down a problem into its smaller constituent parts and then calls for only simple pairwise comparison judgments to develop priorities in each hierarchy" (HARKER und VARGAS, 1987). This could be seen as some of the main advantages of the AHP compared to other methods. In general we use pairwise comparisons to approximate the priorities $w_{i}$ for the influencing factors. Out of the pairwise comparison matrix $P$, these priorities can be estimated (by means of the principal right 
eigenvector; see Saaty, 1995; Saaty 2006) and the group decisions are aggregated by use of the geometric mean:

$$
P=\left(\begin{array}{cccc}
a_{11} & a_{12} & \cdots & a_{1 n} \\
a_{21} & a_{22} & & \\
\vdots & & \ddots & \\
a_{n 1} & & & a_{n n}
\end{array}\right) \approx\left(\begin{array}{c}
w_{1} \\
w_{2} \\
\vdots \\
w_{n}
\end{array}\right) ; \bar{a}_{i j}={ }_{k=1}^{n} a_{i j k} \quad ; k=\frac{m 1}{2}
$$

with $k$ pairwise comparisons, $n$ decision makers of a given $m \times m$ pairwise comparison matrix $P$. The aggregated pairwise comparison matrix $\bar{P}_{\text {is therefore defined as: }}$

$$
\bar{P}=\left(\begin{array}{cccc}
\bar{a}_{11} & \bar{a}_{12} & \cdots & \bar{a}_{1 n} \\
\bar{a}_{21} & \bar{a}_{22} & & \\
\vdots & & \ddots & \\
\bar{a}_{n 1} & & & \bar{a}_{n n}
\end{array}\right) \approx\left(\begin{array}{c}
\bar{w}_{1} \\
\bar{w}_{2} \\
\vdots \\
\bar{w}_{n}
\end{array}\right)
$$

Homogeneity: The difference between the maximum and the minimum of ${ }_{h}, w_{h}$ was calculated to estimate the homogeneity of the group evaluation:

$$
{ }_{h}=\max _{i=1}^{n}\left(\begin{array}{c}
{ }_{h i} \\
)
\end{array} \min _{i=1}^{n}\left({ }_{h i}\right) ; \quad w_{h}=\max _{i=1}^{n}\left(w_{h i}\right) \min _{i=1}^{n}\left(w_{h i}\right)\right.
$$

As we can see from table 2 the final evaluations of the quality managers are not homogeneous. The span between maximum and minimum $\quad h, w_{h}$ amounts from about 0.02 to 0.08 . Therefore, the aggregation to ${ }_{h}^{-}, \bar{W}_{h}$ is connected to a certain loss of information which was further analyzed by use of qualitative interviews with the quality managers. In brief, the different approximations of ${ }_{h}, \bar{W}_{h}$ can be explained by the divergent market positions of the companies and different backgrounds of the

\begin{tabular}{|c|c|c|c|c|c|c|c|c|c|c|c|c|c|c|c|c|c|c|}
\hline & $\sum_{1}$ & $\sum_{1}^{N}$ & $\sum_{i=1}^{n}$ & $\sum_{i=1}^{+}$ & $\sum_{x}^{n}$ & $\sum_{101}^{0}$ & $\sum_{1}$ & 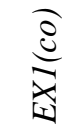 & 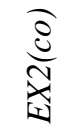 & 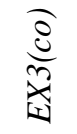 & $\frac{\vec{d}}{\frac{j}{d}}$ & 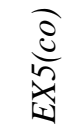 & 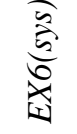 & 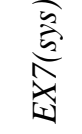 & 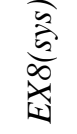 & 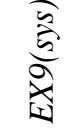 & $\overline{\bar{\omega}}$ & $\hat{\tilde{\omega}}$ \\
\hline $\bar{\phi}_{h}$ & 0.084 & 0.118 & 0.112 & 0.049 & 0.055 & 0.069 & 0.021 & 0.021 & 0.081 & 0.034 & 0.024 & 0.014 & 0.014 & 0.057 & 0.012 & 0.058 & 0.081 & 0.094 \\
\hline $\min$ & 0.057 & 0.072 & 0.085 & 0.026 & 0.035 & 0.045 & 0.007 & 0.006 & 0.044 & 0.011 & 0.007 & 0.006 & 0.002 & 0.044 & 0.000 & 0.020 & 0.041 & 0.073 \\
\hline $\max$ & 0.121 & 0.151 & 0.150 & 0.072 & 0.064 & 0.095 & 0.070 & 0.044 & 0.102 & 0.080 & 0.064 & 0.023 & 0.025 & 0.073 & 0.025 & 0.100 & 0.117 & 0.119 \\
\hline$\Delta \phi_{h}$ & 0.064 & 0.080 & 0.065 & 0.045 & 0.029 & 0.050 & 0.063 & 0.038 & 0.058 & 0.069 & 0.056 & 0.017 & 0.024 & 0.030 & 0.025 & 0.080 & 0.076 & 0.046 \\
\hline $\bar{w}_{h}$ & 0.079 & 0.119 & 0.118 & 0.051 & 0.055 & 0.066 & 0.021 & 0.018 & 0.087 & 0.031 & 0.020 & 0.012 & 0.014 & 0.060 & 0.014 & 0.057 & 0.081 & 0.097 \\
\hline $\min$ & 0.055 & 0.072 & 0.084 & 0.033 & 0.038 & 0.039 & 0.013 & 0.007 & 0.052 & 0.009 & 0.007 & 0.006 & 0.005 & 0.041 & 0.005 & 0.027 & 0.045 & 0.072 \\
\hline $\max$ & 0.115 & 0.147 & 0.144 & 0.068 & 0.069 & 0.091 & 0.068 & 0.048 & 0.110 & 0.076 & 0.068 & 0.025 & 0.024 & 0.069 & 0.024 & 0.099 & 0.115 & 0.125 \\
\hline$\Delta w_{h}$ & 0.060 & 0.075 & 0.061 & 0.035 & 0.032 & 0.051 & 0.055 & 0.041 & 0.059 & 0.067 & 0.062 & 0.020 & 0.019 & 0.029 & 0.019 & 0.072 & 0.070 & 0.053 \\
\hline
\end{tabular}
evaluators (and their organizational position; detailed results can be taken from Pöchtrager, 2011).

Table 2. Final priorities ${ }_{h}$ (MAUA) and $\bar{w}_{h}(\mathrm{AHP})$ of the influencing factors

Estimation of priorities: Table 2 contains the final weighting of the influencing factors of the QM evaluation hierarchy based on MAUA and AHP. There are only slight differences between the final weightings ${ }_{h}, \bar{W}_{h}$. However, after the first evaluation, the results between MAUA and AHP differed significantly (see fig. 2). Therefore, the interviewees were immediately confronted with the results of their evaluations and further analytical outcomes (consistency, sensitivity). All interviewed quality managers modified their first subjective estimations and all of them succeeded in approximating comparable weightings between MAUA and AHP (furthermore, all evaluations were sufficiently consis- 
tent with a consistency ratio $\mathrm{CR}<0.1$; based on a final sensitivity analysis no significant changes of the final approximations were noticed).

Fig. 2. Difference between $\bar{w}_{h}$ (AHP) and $\bar{\phi}_{h}$ (MAUA) and final weighting $\bar{w}_{h}$ (AHP final)

EN1: Management. EN2: Employees. EN3: QM-responsible. EN4: Financial resources / quality costs. EN5: Resources for the infrastructure and working environment. EN6: Product requirements. EN7: Company size. EX1(co): Consumer. EX2(co): Food retailing. EX3(co): Suppliers. co-operations and their market position. EX4(co): Society. EX5(co): Market position of the company. EX6(sys): Special interest group. EX7(sys): Control agency. EX8(sys): Accreditation body. EX9(sys): Legislative body / standard owner.

SYS1: Processes / documentation. SYS2: Measurement, analysis and improvement

\section{Conclusions}

The main aim of the study was to approximate the importance of several elements of a decision hierarchy, the TQM model. Now we know that human factors (employees and QM managers), the core customer of the food industry, the food retailing sector, in combination with system immanent factors are the most important influencing factors for the success vs. failing of a QM system. Furthermore, this study showed that under certain circumstances, a combination of different decision methods could deliver results with higher validity. Increasing validity is obviously connected to the fact that decision makers re-evaluate their results by use of another method, getting deeper insights into the topic. In the end, and after discussing the final results with each quality manager, we generated high trustworthy priorities representing the overall importance of the influencing factors of the comprehensive TQM model. The usage of only one evaluation method would definitely have led to priorities with reduced validity (see fig. 2 representing the first subjective evaluations).

The primary intention of our study was to approximate the QM reality for a whole economic sector. The twofold evaluation process (in combination with further qualitative analysis) helped us to estimate "true" priorities. By using only one evaluation technique, some elements would have been significantly over- or under-estimated. Especially in the case of the AHP, this is probably connected to the hierarchical structure of our model: if only few elements can be found under one criteria, there is a tendency of over-estimating the importance of the priorities of these elements. On the other hand, if we took MAUA only for our evaluation purposes, the priorities of many other elements would have been over-estimated. The largest benefit of the methodological combination is therefore the repeated evaluation and analysis by decision makers which helps them to go deep into the topic and to provide approximations coming close to reality.

\section{REFERENCES}

Addey, J., 2000. Quality myths and legends. Total Quality Management, 11(4-6), 680-685.

Albersmeier, F., Schulze, H., \& Spiller, A., 2010. System Dynamics in Food Quality Certifications: Development of an Audit Integrity System. International Journal on Food System Dynamics, 1, 69-82.

Bayazit. O. \& Karpak. B., 2007. An analytical network process-based framework for successful total quality management, TQM. An assessment of Turkish manufacturing industry readiness. International Journal of Production Economics, 105, 79-96.

Brown, K. \& Dalluege, C.-A., 2004. Analyse mit tiefen Einblicken. Qualitätsmanagement für Projekte. IT-Business News, 26 July, 2004, 24.

Jha, U.C. \& Kumar, S., 2010. Critical Success Factors (CSFs) of TQM: A literature Review \& Analysis. Oxford Business \& Economics Conference Program, June 28-29, 2010, St. Hugh's College, Oxford University, Oxford, UK.

Dyer, R. \& Forman, E., 1991. An Analytic Approach to Marketing Decisions. Prentice-Hall, Englewood Cliffs, New Jersey.

Espejel, J., Fandos. C., \& Flavián, C., 2009. The influence of consumer involvement on quality signals perception. An empirical investigation in the food sector. British Food Journal, 111(11), 1212-1236. 
Fotopoulos, C. \& Psomas, E., 2009. The use of quality management tools and techniques in ISO 9001:2000 certified companies: the Greek case. International Journal of Productivity and Performance Management. 58(6), 564-580.

Harker, P.T., 1989. The Art and Science of Decision Making. In: Golden, B.L. (ed.). The analytic hierarchy process: applications and studies. Springer, Berlin, 3-36.

Khandke, S.S. \& Mayes, T., 1998. HACCP Implementation: a practical guide to the implementation of the HACCP plan. Food Control, 9, 103-109.

Omachonu, V.K., Suthummanon, S., \& Einspruch, N.G., 2004. The relationship between quality and quality cost for a manufacturing company. International Journal of Quality and Reliability Management, 21(3), 277-290.

Pöchtrager. S., 2011. Qualitätsmanagement in der Agrar- und Ernährungswirtschaft. Institutionen. Strukturen und entscheidungsrelevante Faktoren. Heidelberg, Springer.

Pöchtrager, S., Meixner, O., \& Haas, R., 2004. Evaluierung der Erfolgsfaktoren des EFQM-Modells in der österreichischen. Ernährungswirtschaft anhand des Analytischen Hierarchieprozesses. Agrarwirtschaft. Zeitschrift für Betriebswirtschaft, Marktforschung und Agrarpolitik, 53(3), 123-130.

Rampersad, H., 2008. The way to a highly engaged and happy workforce based on the Personal Balanced Scorecard. Total Quality Management, 19(1-2), January-February, 11-27.

Saaty, T.L., 1995. Decision Making for Leaders, The Analytical Hierarchy Process for Decisions in a Complex World. RWS Publications, Pittsburgh.

Saaty, T.L., 2006. Fundamentals of Decision Making and Priority Theory. $2^{\text {nd }}$ Ed. RWS Publications, Pittsburgh.

Tähkäpää, S., Kallioniemi. M., Korkeala, H., \& Maijala, R., 2009. Food control officers perception of the challenges in implementing new food control requirements in Finland. Food Control, 20, 664-670.

Terlaak, A. \& King, A., 2006. The effect of certification with the ISO 9000 Quality Management Standard: A signaling approach. Journal of Economic Behavior \& Organization, 60, 579-602.

Wali, A.A., Deshmukh, S.G., \& Gupta, A.D., 2003. Critical success factors of TQM: a select study of Indian organizations. Production Planning \& Control, 14(1), 3-14.

Wilcock, A., Ball, B., \& Fajumo, A., 2010. Effective implementation of food safety initiatives: Managers' "food safety coordinators" and production workers' perspectives. Food Control, article in press, corrected proof. doi: 10.1016/j.foodcont.2010.06.005, 1-7.

Wilson, T.E. \& Grimlund, R.A., 1990. An Examination of the Importance of an Auditors Reputation. Auditing: A Journal of Practice \& Theory, 9, 43-59.

Yusof, S. \& Aspinwall, E., 2000. Critical success factors in small and medium enterprises: survey results. Total Quality Management, 11(4-6), 448-462. 